\title{
Risk of fall in the elderly: how to evaluate
}

\author{
Risco de queda em idosos: como avaliar
}

Cristiana Borges Pereira

\section{PhD in Medicine, Head of the Group Distúrbios Vestibulares e do Equilíbrio da Divisão de Clinica Neurológica at Hospital das Clínicas, Universidade de São Paulo (HCFMUSP), São Paulo SP, Brazil.}

\section{Correspondence}

Cristiana Borges Pereira

Rua Borges Lagoa, 1080, cj. 106 04038-002 São Paulo SP - Brasil

E-mail:cbpereira@uol.com.br

Conflict of interest

There is no conflict of interest to declare.

Received 21 November 2012

Accepted 28 November 2012
I $\mathrm{n}$ this issue, Pereira et al analyze two important aspects of the elderly: their balance and their risk of falling. Another important aspect of this article regards the use of posturographic tests in clinical practice ${ }^{1}$.

There is an increasing concern about disbalance in older people. Balance and gait impairments in older people increase the risk of falls. One in ten falls in the elderly results in a serious injury such as fractures and head injuries. In an emergency department, $10 \%$ of elderly visits and $6 \%$ of elderly urgent admissions are consequence of falls ${ }^{2}$. Since life expectancy is increasing in most countries, this problem will probably be even worse in the next years. Therefore, there are two points for evaluation: who is at risk of falling, and why this person is at risk. Identifying the factors that increase the risk of fall and managing these factors are complex tasks, since elderly people have several different problems that lead to balance disorders ${ }^{2,3}$. So, it may be interesting, as a first step, to identify who is at risk of falling and, later on, to study the features of this specific population.

Postural control is no longer considered simply a summation of static reflexes but rather a complex skill based on the interaction of dynamic sensorimotor processes. The current model of posture physiology proposes two levels of control. The first is the level of postural body schema and the second is the implementation of postural control ${ }^{4}$. The first level includes the representation of body geometry, body kinematics and body orientation with respect to vertical ${ }^{4}$. The contributions of the somatosensorial, visual and vestibular systems are different for each of these representations and for diverse environmental and task conditions ${ }^{4}$. Thus, the clinical-neurological examination alone may be inaccurate to identify and evaluate posture and balance disorders and scales that evaluate different conditions and tasks may be more helpful. The advantage of such scales is obviously the low cost and the feasible application. Pereira et al. observed that the Berg Balance Scale could identify fall risk in a population of elderly patients ${ }^{1}$, and a previous similar study identified that and the inability to perform the 5 minute Time Up and Go (TUG) test within 30 seconds predicted falls in older women ${ }^{5}$.

The application of posturographic tests, on the other hand, leads to some discussion in the literature ${ }^{4}$. There are different devices and different tests in each device. In a recent review, Chaudhry et al. suggested that the most appropriate method and equipment may depend on the situation specificity ${ }^{6}$. For example, the methods to predict future falls may be different from those which assess balance before and after interventions. Furthermore, one limitation of a simple force plate is that it measures the balance in quiet standing, a condition that is different from those of daily life. Other pieces of equipment are more sophisticated and take into account many of these situations, and balance is more realistically assessed in different conditions, so that they can have a greater applicability.

The authors' intention to analyze those aspects and the editorial board decision to publish this study shows an increasing interest in different points: the evaluation of the elderly population, the comprehension of the issues in the evaluation of posture and balance disorders, and the advantages and limits of the increasing use of posturographic tests. 


\section{References}

1. Pereira VV, Maia RA, Silva SMC. The Functional Assessment Berg Balance Scale is better capable of estimating fall risk in the elderly than the Posturographic Balance Stability System. Arq Neuropsiquiatr 2013;71:5-10.

2. Tinetti ME. Preventing falls in elderly persons. N Engl J Med 2003;348;42-49.

3. Tinetti ME, Williams CS, Gill TM. Dizziness among older adults: a possible geriatric syndrome. Ann Intern Med 2000;132:337-344.
Bronstein AM, Brandt T, Woollacott MH, Nutt JG. Clinical disorders of balance, posture and gait. $2^{\text {nd }}$ ed. London: Arnold, 2004:1-19.

5. Morris R, Harwood RH, Baker R, Sahota O, Armstrong S, Masud T. A comparison of different balance tests in the prediction of falls in older women with vertebral fractures: a cohort study. Age Ageing 2007;36:78-83.

6. Chaudhry H, Bukiet B, Ji Z, Findley T. Measurement of balance in computer posturography: Comparison of methods - a brief review. J Body Mov Ther 2011;15:82-91. 